Original Research

\title{
Evaluation of home medication review for patients with type 2 diabetes mellitus by community pharmacists: a randomised controlled trial
}

\author{
M Rozaini ROSLI (D), Chin F. NEOH David B. WU (D), Nazariah W. HASSAN (D), Mahani MAHMUD (D), \\ Afifah RAHIMI (D), Mahmathi KARUPPANNAN (D) \\ Received (first version): $13-$ Apr-2021 $\quad$ Accepted: 5-Sep-2021 \\ Published online: 9-Sep-2021
}

\begin{abstract}
Background: Successful diabetes treatment requires commitment and understanding of disease management by the patients. Objective: This trial aimed to evaluate the programme effectiveness of home medication review by community pharmacists (HMR-CP) in optimising diabetes care and reducing medication wastage.

Methods: A randomised controlled trial was conducted on 166 patients with Type 2 Diabetes Mellitus (T2DM) who were randomly assigned to the intervention or control groups. The intervention group received HMR-CP at 0-month, 3-month, and 6-month. The primary outcome was haemoglobin A1c (HbA1c) while clinical outcomes, anthropometric data, and humanistic outcomes were the secondary outcomes. For the intervention group, drug-related problems (DRP) were classified according to the Pharmaceutical Care Network Europe Foundation (PCNE). Medication adherence was determined based on the Pill Counting Adherence Ratio (PCAR). The cost of medication wastage was calculated based on the total missed dose by the T2DM patients multiplied by the cost of medication. General linear model and generalised estimating equations were used to compare data across the different time-points within and between the groups, respectively.

Results: No significant difference was observed in the demographic and anthropometric data at baseline between the two groups except for fasting blood glucose (FBG). There was a significant reduction in the HbA1c $(-0.91 \%)$ and FBG $(-1.62 \mathrm{mmol} / \mathrm{L})$ over the study period $(p<0.05)$. A similar observation was noted in diastolic blood pressure (DBP) and total cholesterol (TC) but not in high-density lipoprotein (HDL), and anthropometric parameters. Both utility value and Michigan Diabetes Knowledge Test (MDKT) scores increased significantly over time. As for the intervention group, significant changes in PCAR $(p<0.001)$ and the number of DRP $(p<0.001)$ were noted.

Conclusions: HMR-CP significantly improved the glycaemic control, QoL, medication adherence, and knowledge of T2DM patients as well as reduced the number of DRP and cost of medication wastage. However, the impact of HMR-CP on certain clinical and anthropometric parameters remains inconclusive and further investigation is warranted.
\end{abstract}

\section{Keywords}

Diabetes Mellitus, Type 2; Glycemic Control; Blood Glucose; Glycated Hemoglobin A; Pharmaceutical Services; Pharmacists; Medication Adherence; Disease Management; Program Evaluation; Linear Models; Randomized Controlled Trials as Topic; Malaysia

\section{INTRODUCTION}

Diabetes is looming as one the most serious global epidemic in the $21^{\text {st }}$ century. It is associated with significant morbidity and mortality. ${ }^{1}$ In Malaysia, the prevalence of diabetes among adults increased from $11.2 \%$ (i.e. an estimated 1.9 million in 2011) to $13.4 \%$ in 2015 (i.e. an

M Rozaini ROSLI. BPharm, MBA. PhD. Faculty of Pharmacy, University of Technology MARA (UiTM). Selangor (Malaysia). zaini 0601@yahoo.com

Chin Fen NEOH. PhD. Senior Lecturer. Faculty of Pharmacy, University of Technology MARA (UiTM). Selangor (Malaysia). chinfenneoh@gmail.com

David Bin-Chia WU. PhD. Director. Asian Centre for Evidence Synthesis in Population, Implementation and Clinical Outcomes, Health and Well-Being Cluster, Global Asia in the 21st Century Platform, Monash University Malaysia, Sunway Town, Selangor (Malaysia).david.wu@monash.edu

W Nazariah W HASSAN. M.D. Family medicine specialist, Pasir Mas City Health Clinic. Kelantan (Malaysia).

drnazariah@moh.gov.my

Mahani MAHMUD. M.D. Senior Medical Officer at Pasir Mas City

Health Clinic, Hospital Street, Pasir Mas, Kelantan, Malaysia. drmahani@moh.gov.my

Afifah RAHIMI. BPharm. Senior Pharmacist at Pasir Mas City Health Clinic, Hospital Street, Pasir Mas, Kelantan, Malaysia. afifahrahimi@moh.gov.my

Mahmathi KARUPPANNAN. PhD. Senior Lecturer, Faculty of Pharmacy, University of Technology MARA (UiTM). Selangor (Malaysia).mahmathi@uitm.edu.my estimated population of 2.7 million) and $18.3 \%$ in 2019 (i.e. an estimated population of 3.9 million). ${ }^{2}$ By comparison, the prevalence of diabetes among adults in Malaysia is much higher than the average prevalence in the South-East Asia region (8.4\%) based on a survey in $2014 .^{3}$ In view of the worsening epidemic, the Ministry of Health $(\mathrm{MOH})$ has undertaken various preventive and awareness programmes such as health campaigns, home medication review (HMR) by pharmacists, and medication therapy adherence clinic for diabetes patients. Despite these efforts, the prevalence continues to rise.

HMR, also known as pharmacist-led medication review, is defined as "a systematic assessment of consumer's medication and management of those medications to optimise health outcome of the consumer and to identify any potential medication-related issues within the framework of the quality use of medicine". ${ }^{4}$ In many developed countries such as Australia, New Zealand, the United Kingdom (UK), and the United States of America (US), the models of pharmacist-led medication review in the community or residential aged care setting are very well established. ${ }^{4}$ Numerous studies have demonstrated that HMR could benefit patients with multiple chronic conditions, increasing age, or adverse social circumstances. The benefits were also observed among patients with 

patients with type 2 diabetes mellitus by community pharmacists: a randomised controlled trial. Pharmacy Practice 2021 Jul-

complex drug regimen and those with a lack of knowledge or skill on using medications or medication-related devices. ${ }^{5,6}$

In Malaysia, HMR was initiated by the Pharmaceutical Services Division, Ministry of Health (MOH). In 2011, the first protocol for HMR was published to standardise the practice of HMR services by all the pharmacists under $\mathrm{MOH}$ facilities. ${ }^{7}$ Subsequently, in 2019, $\mathrm{MOH}$ published the second version of HMR, known as Home Care Pharmacy Services (HCPS). ${ }^{8}$ HCPS is one of the pharmaceutical care programmes to ensure the continuity of care upon returning from health facilities i.e. outpatient or inpatient settings to their homes in order to facilitate efficient and quality use of medicines. The entire procedure of HCPS involves extensive and systematic activities that include drug reconciliation and medication analysis for both prescription and non-prescription drugs. $\mathrm{MOH}$ pharmacists from hospitals or health clinics are in charge of conducting the HMR or HCPS. The service focuses primarily on four types of patients, namely psychiatry, geriatrics, stroke, and paediatrics. All the HMR or HCPS activities are fully funded by the government. To date, only two studies regarding HMR services have been conducted in Malaysia. Both involved services provided by the $\mathrm{MOH}$ pharmacists to T2DM patients in $\mathrm{MOH}$ health clinics. The findings revealed that HMR significantly reduced the percentage of $\mathrm{HbA} 1 \mathrm{C}$ by $1.04 \%$, apart from improving patients' knowledge about the disease and quality of life (QoL). ${ }^{9,10}$

Globally, there are very few published studies that evaluated the HMR services provided by community pharmacists. ${ }^{11}$ Likewise, little is known about the potential role of community pharmacists in providing such services in Malaysia. The community pharmacists are one of the frontliners in the primary healthcare setting as they are responsible to ensure that medication use by the patients is safe, effective, and efficient. ${ }^{12,13}$ In Malaysia, the number of community pharmacists has significantly increased from 1,854 in the year of 2011 to 3,094 in the year $2016 .{ }^{14}$ With the increasing manpower, the evolution in the role of community pharmacists in pharmaceutical care provision is therefore anticipated, and HMR could be one of it. HMR is a comprehensive clinical review of a patient's medicines at their homes by accredited community pharmacists (HMR$\mathrm{CP}$ ) upon referral from the family medicine specialist (FMS), medical officers (MO), or general practitioner (GP). This service is believed to be particularly beneficial for T2DM patients who live independently in the community. ${ }^{15}$ However, further investigations are warranted to establish this association. This randomised clinical trial (RCT) aimed to evaluate the effectiveness of the HMR-CP programme in optimising diabetes care in Malaysia. The clinical impact of HMR-CP (i.e. glycaemic control, blood pressure, anthropometric parameters, lipid profiles), number of DRP resolved or prevented, rate of severe adverse events, hospitalisation, and humanistic outcomes (i.e. QoL, patients' knowledge about the disease, and medication adherence) among patients with T2DM were evaluated.

\section{METHODS}

\section{Ethics approval and trial registration}

The study was approved by the Medical Research \& Ethics Committee (MREC), Ministry of Health (MOH) [Reference number: NMRR-17-2348-37624(IIR)], and the UiTM Research Ethics Committee (Reference number: $\mathrm{REC} / 224 / 18$ ). This trial was also registered with the Australian-New Zealand Clinical Trial Registry (ANZCTR) (ACTRN12618000839202).

\section{Study design and setting}

An RCT was conducted between March to December 2018. T2DM patients were recruited from the Bandar Pasir Mas Healthcare Clinic in Kelantan, Malaysia. This clinic is one of the public primary healthcare clinics in the state of Kelantan, serving a total of 189,292 outpatients in the surrounding areas. ${ }^{16}$ Kelantan is located in the NorthEastern region of Peninsular Malaysia. In 2012, the state of Kelantan recorded the lowest rate of diabetes patients (14.9\%) with a satisfactory $\mathrm{HbA1c}$ level of $\leq 6.5 \%$ among all the states in Malaysia. ${ }^{17}$ Thus, it was purposively chosen as the site of this trial.

\section{Study population}

The inclusion criteria for this RCT were (i) adult patients age 18 years and above, (ii) latest $\mathrm{HbA} 1 \mathrm{c}$ of more than $6.5 \%$, (iii) took five or more medications for long-term maintenance therapy or taking more than 12 doses of medications daily, (iv) stayed within $25 \mathrm{~km}$ radius from the Bandar Pasir Mas Health Clinic and (v) can be contacted through phone. These inclusion criteria were based on the $\mathrm{MOH}$ guideline that specified the requirements for patients to be included in $\mathrm{HMR}^{7}$

Patients were excluded if they endured mental health problems, were dependant on their caretakers, unable to communicate in English or Bahasa Malaysia, had no permanent residential address, with blood disorders (i.e. haemolytic anaemia, haemoglobinopathy, chronic lymphocytic leukaemia), or diagnosed with Stage 3 to 5 of chronic kidney disease. ${ }^{18,19}$ A detailed explanatory statement was given to them and informed consent was signed by all participants prior to the commencement of the study. The participants were randomly assigned to an intervention group (i.e. receiving $\mathrm{HMR}-\mathrm{CP}$ ) or a control group (i.e. not receiving HMR-CP). All participants were followed up for six months.

\section{Sample size calculation}

The primary outcome of this study was the change in $\mathrm{HbA1c}$ between HMR-CP and control groups. A reduction of $1 \% \mathrm{HbA} 1 \mathrm{c}$ was associated with a $21 \%$ risk reduction of death related to diabetes, $37 \%$ risk reduction for microvascular complications, $21 \%$ risk reduction of diabetes related-end point, and $14 \%$ risk reduction of myocardial infarction. $^{20}$ Hence, a $1 \%$ reduction in HbA1c was considered to be clinically relevant. Based on an expected mean difference of $\mathrm{HbA} 1 \mathrm{c}$ of $1.04 \%$ between the groups, standard deviation of $2.16 \%$, power of $80 \%$, and a twotailed alpha of 0.05 , the required sample size was calculated to be at least 69 intervention subjects and 69 control subjects. ${ }^{10}$ Taking into account a dropout/loss to follow-up rate of $20 \%$, at least 166 participants were required (i.e. 83 experimental subjects and 83 control subjects). The sample size was calculated using PS Power and Sample Size Calculations (Version 3.0, Dupont \& Plummer, 2009). 

patients with type 2 diabetes mellitus by community pharmacists: a randomised controlled trial. Pharmacy Practice 2021 Jul-

\section{Intervention}

The HMR protocol established by the Pharmaceutical Services Division, $\mathrm{MOH}$ was used as the reference to develop the forms and materials for the HMR-CP programme. $^{7}$ Pilot testing was conducted using all the materials to determine the feasibility of the HMR-CP programme in the community setting and to assess the comprehension level of the FMS/MO and the community pharmacists towards the developed programme materials. Any feedback and comments were taken into consideration. All language discrepancies and grammar mistakes were rectified before the materials for the HMR$\mathrm{CP}$ programme were finalised.

A toolkit that comprised a set of standardised forms was prepared. It was provided to all the community pharmacists who were involved in this programme to ensure that consistent information was delivered to all study participants. The community pharmacists in Kelantan were invited to join this programme through the Malaysian Community Pharmacy Guild (MCPG) Kelantan branch. To enlist the help of MCPG, a letter was sent to the President of the Malaysian Community Pharmacy Guild (MCPG) and a presentation of this project was given at one of MCPG's regular seminars. A total of seven community pharmacists who fulfilled the inclusion criteria (i.e. hold a valid Licence A) and agreed to participate in the HMR-CP programme were recruited and trained. All FMS/MO involved in diabetes care at the Bandar Pasir Mas Health Clinic participated in this study. A one-day training session was conducted by the researchers to train the community pharmacists and other FMS/MO on how to conduct HMR$\mathrm{CP}$, fill-up the forms, and write the report. The community pharmacists were also briefed on the type of medication available at the Bandar Pasir Mas Health Clinic and the routine management of T2DM by the FMS.

The study intervention (i.e. HMR-CP) involved both HMR visits performed by community pharmacists and review by FMS/MO. The community pharmacists visited T2DM participants' houses every three months (i.e. baseline, 3month, and 6-month). The three time-points (i.e. 0-, 3-, and 6 -month) were selected with the aims of determining the short-term and long-term impacts of the HMR-CP programme on both clinical and humanistic outcome measures.

Within one week of obtaining the patients' consent, the researcher contacted those who were assigned to the HMR-CP group to arrange an appointment for the community pharmacists to make the first visit to their homes. Community pharmacists were provided with patient profiles, medication history, clinical, and anthropometric data for the counselling session. Each HMR visit lasted between 20 and 45 minutes in which the community pharmacists provided tailored counselling to the participants about medication adherence, lifestyle modification, and self-monitoring blood glucose monitoring at home. The counselling on medication adherence involved emphasising the importance of adhering to prescribed medication, calculating the balance of pills to determine the adherence, assessing patient's long-term and short term goals, and creating awareness on the common side effects of the medication, as well as reminding them of the consequences and action to be taken in case of a missed dose. For lifestyle modification, community pharmacists discussed nutritional intake in terms of the types of food, quantity per serving, and timing of meals. Patients were also counselled on suitable physical activities according to their current health conditions, the importance of weight management, and glucose monitoring. Any hospital admission was also collected and recorded. After each HMR visit, the community pharmacists completed a report to provide feedback (including any detected drug-related problems) to the FMS/MO so that adjustments in patients' medication regimens could be made where necessary.

Participants who were randomised to the control group were provided with usual care without any active intervention. They received routine treatment by MOs in the health clinic and were contacted through phone by the researcher to remind them about their visits to the health clinic for blood sampling and data collection. The researcher interviewed them through the phone to obtain their responses for the MDKT and EQ-5D-5L questionnaires. All the responds were recorded in hardcopy of MDKT and EQ-5D-5L questionnaires.

\section{Primary outcome}

For diabetes, $\mathrm{HbA} 1 \mathrm{c}$ is a clinically relevant parameter and thus the preferred test for assessing glycaemic control in people with diabetes. The value of $6.5 \%$ is recommended as the cut-off point for the diagnosis of diabetes. ${ }^{19,21,22}$ The baseline HbA1c value was retrieved from the patients' medical records (e.g. not more than three months). About $5 \mathrm{~mL}$ of venous blood was withdrawn by an appointed nurse or MO during the follow-up at 3-month and 6-month for both groups. Blood samples were sent to the laboratory in the Bandar Pasir Mas Healthcare Clinic and the HbA1c levels were documented by investigators using a standardised, investigator-developed data collection form.

\section{Secondary outcomes}

Clinical and anthropometric parameters: In this study, secondary outcomes included fasting blood glucose (FBG), and diastolic blood pressure (DBP) were obtained at baseline, 3-month, and 6-month follow-up. Similarly, weight, height, and body mass index (BMI) were measured and documented using a standardised, investigatordeveloped data collection form at similar intervals. All the secondary outcome measures for both groups were recorded by an appointed nurse at baseline, 3-month, and 6-month follow-up.

Medication-related issues and hospitalisation: In this study, DRP was only recorded for the intervention group during each HMR-CP visit. Classification for DRP(Version 8.02) developed by the Pharmaceutical Care Network Europe Foundation (PCNE) was used with permission to classify the drug-related problems. ${ }^{23}$ Twenty percent of patients in the intervention group were randomly chosen and the classification of their DRP was discussed within a multidisciplinary team of FMS/MO, community pharmacists, and researchers. Any discrepancy was resolved with team consensus. The PCNE code for the remaining $80 \%$ of patients was determined by the 
researchers. In addition, hospitalisation or visits to the emergency department due to adverse events of antidiabetic medications or hypoglycaemic attacks during the six months of the study were recorded. For the HMR-CP group, patients were asked about hospital admission by the community pharmacist during home visits. As for the control group, the information on hospital admission was obtained via follow-up phone calls.

Medication adherence: It is well-known that treatment failure due to poor medication adherence can result in many re-hospitalisations, poor disease outcomes, and increased healthcare costs. ${ }^{24}$ In this trial, medication adherence for the intervention group was determined based on pill counting adherence ratio (PCAR) and subsequently documented in the HMR-CP form. During each HMR-CP visit, the community pharmacist calculated the remaining pills of the T2DM patients to check if the balance tallied it with what they should have based on the prescribing record. In the Malaysian health clinic setting, each patient is supplied with medication by the pharmacy department monthly. Before dispensing, the pharmacist at the health clinic will ask the patient about the balance of medication before supplying them with medication that is sufficient for one month.

$$
\text { PCAR }=\frac{\text { Total dose dispensed }- \text { Total dose missed }}{\text { Total dose dispensed }}
$$

The formula above was used to calculate the adherence ratio. ${ }^{25}$ The higher the ratio, the higher the patient's adherence rate towards medication. The cost of medication wastage was then calculated based on the total dose missed by the T2DM patients multiplied by cost of medication paid by the $\mathrm{MOH}$.

\section{Study instruments}

The permission to use the five-level EuroQol-5 Dimension Questionnaire (EQ-5D-5L) and the Malaysian Version of the Michigan Diabetes Knowledge Test (MDKT) were obtained from the respective authors or organisations before the commencement of the study. As a recent study reported that no significant change was observed in the QoL of patients within a short intervention period, the QoL and participants' knowledge were only assessed at baseline and 6-month follow-up. ${ }^{26}$ For those in the HMR-CP group, these data were collected during the HMR-CP home visits while participants in the control group provided these data via phone calls. The difference in the data collection method between the two groups arose since the community pharmacists did not have any direct contact with patients in the control group. Therefore, it was more feasible for the researcher to collect these data via phone calls. Despite the difference, the tools used were the same for both groups.

The general health of the participants was assessed using the reliable and validated EQ-5D-5L questionnaire. ${ }^{27}$ The descriptive index obtained was converted to a utility value. EQ-5D-5L is a descriptive system of health-related QoL states that consists of five dimensions (i.e. mobility, selfcare, usual activities, pain/discomfort, and anxiety/depression), each of which can be responded in five levels of severity (i.e. no problem, slight problem, moderate problem, severe problem, extreme problem).
The validated English and Malay-translated versions of EQ5D-5L from EuroQoL was used and the recently published Malaysian EQ-5D-5L value set was applied for the health state valuation in this $\mathrm{RCT}{ }^{28}$

The patient's self-management is regarded as one of the critical factors to ensure good control of blood glucose level and high QoL among diabetic patients. To achieve good self-disease management, diabetic patients must possess sufficient knowledge and skills for their daily care management. ${ }^{29}$ In this RCT, the participant's knowledge about diabetes was measured using the Malaysian version of 14-item Michigan Diabetes Knowledge Test (MDKT). This instrument has been proven to be a reliable and valid measure of diabetes knowledge that can be used in both clinical and research practice. ${ }^{30}$

\section{Randomisation procedure, concealment of allocation, and blinding}

A set of random numbers was generated using Microsoft Excel and was kept in a sealed envelope by an independent researcher. Blinding refers to the concealment of group allocation from one or more individuals who are involved in an RCT. ${ }^{31}$ In this single-blinded RCT, the appointed nurse who took the blood samples for clinical outcomes (i.e. glycaemic parameters, blood pressure, and lipid profiles), and also anthropometric data [i.e. weight, body mass index $(\mathrm{BMI})]$ was blinded from knowing the group of patients.

\section{Statistical analysis}

All data were analysed using statistical software IBM SPSS version 24 (IBM Corp, Chicago, Illinois, USA). Non-normally distributed data were log-transformed into a normalised distribution before analysis. Intention-to-treat (ITT) population analysis was performed on a complete set of data after the missing data were imputed using the last observation carried forward (LOCF) method. Categorical variables were presented using descriptive statistics i.e. frequency and percentage whereas continuous data were presented as mean (standard deviation). Chi-square was used for the comparisons of categorical data. The independent t-test was used to compare the baseline parameters between both groups. In addition, repeated measures analysis using General Linear Model (GLM) was used to compare data across the different time-points within the group. The difference in changes from baseline to 6-month $\mathrm{HbA1c}$ between the control and intervention groups was analysed using the Generalised Estimating Equations (GEE) to determine the correlation of measurements at different time points for each individual. In the regression model, age, gender, ethnicity, BMI, FBG, intervention, and time were considered as covariates or factors. FBG was included in the model for adjustment as it was not comparable between the two groups at the baseline. The same linear model was also applied to all the secondary outcomes and the clinical parameters that were used to simulate the lifetime health outcome. Models with intervention $\mathrm{x}$ time interaction effects were also examined to determine how effectiveness changed over time according to the intervention assignment. A priori level of significance of 0.05 was set for the study. 


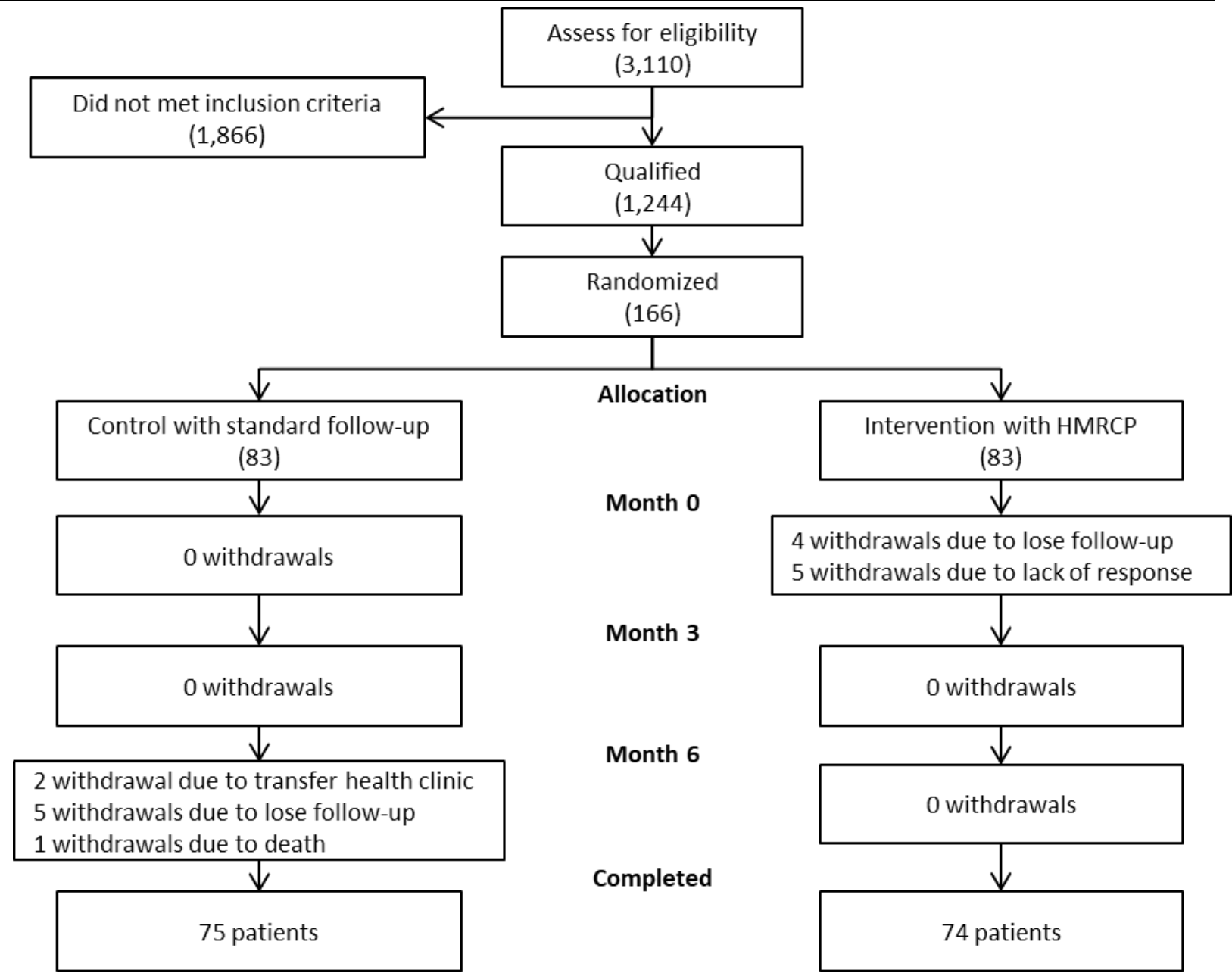

Figure 1. CONSORT diagram of patients flows through the study

\section{RESULTS}

Of the 3,110 patients screened for eligibility using the National Diabetic Registry at the Bandar Pasir Mas Health Clinic, 1,244 of them fulfilled the inclusion criteria and were approached by the researchers. A total of 166 patients with T2DM agreed to participate and were then randomly assigned to either HMR-CP or control groups (Figure 1). However, 17 of them [HMR-CP group, $n=9$ (10.8\%); control group, $n=8(9.6 \%), p=0.798$ ] dropped out of the study at the 6-month follow-up, thus giving rise to an attrition rate of $10.2 \%$. The demographic characteristics [i.e. age $(p=0.340)$, gender $(p=0.589)$, and ethnicity $(p=0.155)]$ and the clinical profiles [i.e. use of insulin $(p=0.202), B M I$ $(p=0.558)$, HbA1c $(p=0.060)$, FBG $(p=0.045)$, and DBP $(p=0.690)]$ were similar between the dropouts and the participants who remained in the study.

The mean age of the 166 participants was 62.0 years old (SD 7.93). The majority were females (75.3\%) and Malays (98.8\%). The mean HbA1c level and mean BMI were 9.91\% (SD 2.16) and $27.79 \mathrm{~kg} / \mathrm{m}^{2}$ (SD 5.02), respectively. Table 1 shows the demographic characteristics for both groups. There was no significant difference between both groups at baseline, except for the proportion of baseline FBG $(p=0.045)$. The participants assigned to the control group had a lower baseline FBG $(9.5 \mathrm{mmol} / \mathrm{L}, \mathrm{SD} 3.81)$ compared with the intervention group (10.9 $\mathrm{mmol} / \mathrm{L} \mathrm{SD} \mathrm{4.56).} \mathrm{In} \mathrm{both}$ groups, the majority of the participants were females and of Malay ethnicity. The mean BMI for each group was 28 $\mathrm{kg} / \mathrm{m}^{2}$, indicating most of the participants were either overweight or obese. Almost all participants were prescribed with statin [HMR-CP group, $n=81$ (97.6\%); control group, $n=83(100.0 \%), p=0.155]$. Apart from that, no other significant differences were observed between the two groups at baseline for all the above mentioned outcome measures (i.e. glycaemic parameters, anthropometric parameters, blood pressure, lipid profiles, QoL, and MDKT score).

Furthermore, the incidence of hospitalisation was comparable between both groups [HMR-CP group, $n=3$ (3.6\%); control group, $n=6$ (7.2\%), $p=0.304]$. No serious adverse event was reported for both groups throughout the intervention period apart from one participant in the control group who passed away due to a heart attack.

Table 2 summarises the changes of glycaemic parameters and all the outcome measures across all time-points for the HMR-CP and control groups. Significant reduction in $\mathrm{HbA1c}$ from $10.29 \%$ (SD 2.08) to $9.32 \%$ (SD 2.19) $(p<0.001$ ) was noted within the HMR-CP group while no significant change was observed in the control group. As revealed in the GEE analysis, HbA1C decreased significantly over time in the HMR-CP group at 6-month follow-up (beta $=-0.386,95 \% \mathrm{Cl}$ : -0.647 to $-0.126, p=0.004$ ) after adjusting for baseline $\mathrm{BMI}$, 
Rosli MR, Neoh CF, Wu DB, Hassan NW, Mahmud M, Rahimi A, Karuppannan M. Evaluation of home medication review for patients with type 2 diabetes mellitus by community pharmacists: a randomised controlled trial. Pharmacy Practice 2021 JulSep;19(3):2397.

https://doi.org/10.18549/PharmPract.2021.3.2397

\begin{tabular}{|c|c|c|c|}
\hline Characteristics & Control group ( $n=83$ ) & HMR-CP group ( $n=83$ ) & p-value \\
\hline Age (years), mean (SD) & $61.36(8.50)$ & $62.54(7.36)$ & $0.340^{\mathrm{a}}$ \\
\hline Gender, n (\%) & $\begin{array}{l}22(26.5) \\
61(73.5)\end{array}$ & $\begin{array}{l}19(22.9) \\
64(77.1)\end{array}$ & $0.589^{b}$ \\
\hline Ethnicity, n (\%) & $\begin{array}{c}81(97.6) \\
2(2.4)\end{array}$ & $\begin{array}{c}83(100.0) \\
0(0.0)\end{array}$ & $0.155^{b}$ \\
\hline Anthropometric data, mean (SD) & $\begin{array}{c}155.58(7.29) \\
66.84(13.83) \\
27.56(5.06) \\
\end{array}$ & $\begin{array}{c}156.04(7.81) \\
68.46(14.60) \\
28.02(5.01) \\
\end{array}$ & $\begin{array}{l}0.697^{\mathrm{a}} \\
0.464^{\mathrm{a}} \\
0.558^{\mathrm{a}}\end{array}$ \\
\hline $\begin{array}{r}\mathrm{HbA}_{1 \mathrm{c}}(\%) \\
\text { FBG }(\mathrm{mmol} / \mathrm{L}) \\
\text { DBP }(\mathrm{mmHg})\end{array}$ & $\begin{array}{c}9.60(2.21) \\
9.54(3.81) \\
75.69(10.21)\end{array}$ & $\begin{array}{l}10.23(2.08) \\
10.93(4.56) \\
76.30(9.61)\end{array}$ & $\begin{array}{l}0.060^{\mathrm{a}} \\
0.045^{\mathrm{a}, \mathrm{c}} \\
0.690^{\mathrm{a}}\end{array}$ \\
\hline $\begin{array}{r}\text { Metformin } \\
\text { Gliclazide } \\
\text { Glibenclamide } \\
\text { Acarbose } \\
\text { Insulin }\end{array}$ & $\begin{array}{l}76(91.6) \\
42(50.6) \\
3(3.6) \\
4(4.8) \\
47(56.6)\end{array}$ & $\begin{aligned} & 70(84.3) \\
& 36(43.4) \\
& 2(2.4) \\
& 2(2.4) \\
& 55(66.3)\end{aligned}$ & $\begin{array}{l}0.153^{b} \\
0.351^{b} \\
0.650^{b} \\
0.406^{b} \\
0.202^{b}\end{array}$ \\
\hline Anti-hypertensive medicine & $82(98.8)$ & $83(100.0)$ & $0.316^{b}$ \\
\hline Cholesterol-lowering medicine & $83(100.0)$ & $81(97.6)$ & $0.155^{b}$ \\
\hline Respiratory medicine $^{d}$ & $5(6.0)$ & $2(2.4)$ & $0.247^{6}$ \\
\hline Other type(s) of medicine ${ }^{e}$ & 76 (91.6) & $70(84.3)$ & $0.153^{\mathrm{b}}$ \\
\hline $\begin{array}{r}\text { Medication cost per month, mean (SD) } \\
\text { Total medicine cost (MYR) } \\
\text { Anti-diabetic medicine cost (MYR) } \\
\text { Other medicine cost (MYR) }\end{array}$ & $\begin{array}{c}59.59(46.78) \\
35.18(40.29) \\
48.68(220.31)\end{array}$ & $\begin{array}{l}65.48(39.90) \\
40.71(28.32) \\
25.60(27.53)\end{array}$ & $\begin{array}{l}0.384^{\mathrm{a}} \\
0.308^{\mathrm{a}} \\
0.345^{\mathrm{a}}\end{array}$ \\
\hline $\begin{array}{l}\text { 'Independent t-test } \\
{ }^{\mathrm{b}} \text { Chi-square test } \\
{ }^{\mathrm{c}} \text { Log-transformed independent t-test } \\
{ }^{\mathrm{d}} \text { Bronchodilators, Anti-inflammatory agents, and Leukotriene } \\
\text { eVitamin, Antibiotics and as-needed based medicine }\end{array}$ & gonists & & \\
\hline
\end{tabular}

FBG, and demographic variables. A similar observation was noted for FBG. Significant reduction in the FBG was noted within the HMR-CP group from $10.93 \mathrm{mmol} / \mathrm{L}$ (SD 4.56) to $9.31 \mathrm{mmol} / \mathrm{L}$ (SD 4.38) ( $p=0.002)$. The opposite was observed in the control group whereby FBG increased from $9.54 \mathrm{mmol} / \mathrm{L}$ (SD3.81) to $9.85 \mathrm{mmol} / \mathrm{L}$ (SD 3.77) ( $p=0.086)$. The GEE analysis also showed that FBG significantly decreased over time in the HMR-CP group at 6-month follow-up (beta $=-0.038,95 \% \mathrm{Cl}$ : -0.069 to $-0.008, p=0.015$ ) after adjusting for baseline values and demographic variables. For all the outcomes, there were $10.8 \%$ of missing values at most. Thus, they were not associated with the main covariables and assumed to be missing at random.

Within the control group, there was a significant weight reduction $(p=0.030)$ and $B M I(p=0.039)$ as compared to the HMR-CP group that reported no significant changes in these two parameters. Despite adjusting for the baseline values and demographic variables, changes in other anthropometric parameters such as weight $(p=0.409)$ and BMI $(p=0.575)$ did not differ significantly between the groups over time. On the other hand, DBP increased significantly within the control group $(p=0.005)$ as indicated by the GLM analysis. The GEE analysis showed a significant decrease of DBP over time in the HMR-CP group at 6month follow-up (beta $=-1.459,95 \% \mathrm{Cl}$ : -2.889 to -0.029 , $p=0.046)$.
The change in TC within each group was significant but not for HDL (Table 3). Likewise, the GEE analysis showed a significant decrease of TC over time in the HMR-CP group at 6-month follow-up (beta $=-0.315,95 \% \mathrm{Cl}$ : -0.444 to -0.186 , $\mathrm{p}<0.001)$ after adjusting for baseline numbers and demographic variables. However, a significant reduction in HDL over time was noted in the HMR-CP group at 6-month follow-up (beta $=-0.035,95 \% \mathrm{Cl}:-0.063$ to $-0.007, p=0.015$ ) after adjusting for baseline BMI, FBG and demographic variables.

As shown in Table 3, both the utility value and MDKT score increased significantly within the HMR-CP group. However, for the control group, the utility value decreased significantly while the MDKT score increased significantly. The differences in the utility and MDKT scores pre- and post-intervention were significant between groups $(p<0.001)$. Likewise, the GEE analysis showed a significant increase of utility value over time in the HMR-CP group at 6-month follow-up (beta $=0.049,95 \% \mathrm{Cl}$ : 0.036 to 0.063 , $\mathrm{p}<0.001$ ) after adjusting for baseline values and demographic variables. A similar observation was noted in the knowledge score (Table 3). MDKT score increased significantly over time in the HMR-CP group at 6-month follow-up (beta $=1.040,95 \% \mathrm{Cl}: 0.760$ to $1.319, \mathrm{p}<0.001$ ) after adjusting for baseline BMI, FBG, and demographic variables.

Table 4 outlines the characteristics of DRP based on the PCNE classification. The five components of PCNE included 
Rosli MR, Neoh CF, Wu DB, Hassan NW, Mahmud M, Rahimi A, Karuppannan M. Evaluation of home medication review for patients with type 2 diabetes mellitus by community pharmacists: a randomised controlled trial. Pharmacy Practice 2021 JulSep;19(3):2397.

https://doi.org/10.18549/PharmPract.2021.3.2397

\begin{tabular}{|c|c|c|c|c|c|c|c|c|}
\hline & \multirow{2}{*}{$\mathrm{n}$} & \multicolumn{3}{|c|}{ Mean (SD) } & \multirow{2}{*}{$\begin{array}{c}\text { Within group } \\
p \text {-value }\end{array}$} & \multirow{2}{*}{$\begin{array}{l}\text { 3-month- } \\
\text { baseline }\end{array}$} & \multirow{2}{*}{$\begin{array}{l}\text { 6-month- } \\
\text { baseline }\end{array}$} & \multirow{2}{*}{$\begin{array}{c}\begin{array}{c}\text { Interaction } \\
\text { p-value }\end{array} \\
\text { ITT }\end{array}$} \\
\hline & & Baseline & 3-month & 6-month & & & & \\
\hline \multicolumn{9}{|c|}{ Glycaemic parameters } \\
\hline HbA1c (\%) & & & & & & & & $0.004 *$ \\
\hline HMR-CP group & 83 & $10.29(2.08)$ & $10.00(2.19)$ & $9.32(2.16)$ & $<0.001 *$ & $-0.22(1.23)$ & $-0.91(1.70)$ & \\
\hline Control group & 83 & $9.60(2.21)$ & $9.89(2.27)$ & $9.60(1.88)$ & 0.134 & $0.29(1.20)$ & $-0.01(1.70)$ & \\
\hline$F B G(\mathrm{mmol} / \mathrm{L})$ & & & & & & & & $0.015^{c *}$ \\
\hline HMR-CP group & 83 & $10.93(4.56)$ & 9.60 (3.99) & $9.31(4.38)$ & $0.002^{c} *$ & $-1.33(4.67)$ & $-1.62(4.80)$ & \\
\hline Control group & 83 & $9.54(3.81)$ & $10.59(4.59)$ & $9.85(3.77)$ & $0.086^{c}$ & $1.05(4.38)$ & $0.31(4.26)$ & \\
\hline \multicolumn{9}{|c|}{ Anthropometric measurements } \\
\hline Weight $(\mathrm{kg})$ & & & & & & & & 0.409 \\
\hline HMR-CP group & 83 & $68.46(14.60)$ & $68.08(14.27)$ & $68.22(14.43)$ & 0.184 & $-0.38(1.67)$ & $-0.24(2.24)$ & \\
\hline Control group & 83 & 66.84 (13.83) & $66.32(13.66)$ & 66.45 (13.91) & $0.030 *$ & $-0.53(1.68)$ & $-0.39(2.04)$ & \\
\hline$B M I\left(\mathrm{~kg} / \mathrm{m}^{2}\right)$ & & & & & & & & 0.575 \\
\hline HMR-CP group & 83 & $28.02(5.01)$ & $27.87(4.96)$ & $27.93(5.04)$ & 0.224 & $-0.15(0.67)$ & $-0.09(0.91)$ & \\
\hline Control group & 83 & $27.56(5.06)$ & $27.35(5.01)$ & $27.40(5.09)$ & $0.039^{*}$ & $0.21(0.71)$ & $-0.16(0.87)$ & \\
\hline Diastolic BP $(\mathrm{mmHg})$ & & & & & & & & $0.046^{*}$ \\
\hline HMR-CP group & 83 & 76.30 (9.61) & $76.52(8.72)$ & $76.33(9.89)$ & 0.962 & $0.22(7.38)$ & $0.02(9.68)$ & \\
\hline Control group & 83 & 75.69 (10.21) & $78.46(10.50)$ & $78.65(9.21)$ & $0.005^{*}$ & $2.77(9.83)$ & $2.96(9.13)$ & \\
\hline
\end{tabular}

the problem, cause of the problem, planned intervention, acceptance of intervention proposed, and outcome of the intervention. The frequency of DRP reduced from 68 to 43 $(p<0.001)$ and the causes of the problem also declined from 150 to $72(p<0.001)$ over time in the HMR-CP group. Upon the completion of the first HMR-CP session, the most commonly planned interventions were drug counselling for patients ( $n=66,48.18 \%)$ and informing the prescriber about the findings ( $n=65,47.45 \%$ ) based on the HMR-CP report, for example, whether the patient uses/takes less drug than prescribed or does not take the drug at all, inappropriate storage of drugs, inappropriate timing of consumption or dosing intervals, etc. Next, most of the proposed intervention were accepted, either with full $(n=22,31.88 \%)$ or partial $(n=30,43.48 \%)$ implementation. Likewise, the majority of the identified DRP were either totally $(n=23$, $33.82 \%)$ or partially $(n=28,41.18 \%)$ solved.

As summarised in Table 5, a significant increase of PCAR from 0.20 (SD 0.21) to 0.51 (SD 0.28) $(p<0.001)$ was noted. There was also a significant reduction in the cost of medication wastage from MYR 21.73 (34.86) to 12.55
(16.41) $(p=0.014)$ among those who received HMR-CP.

\section{DISCUSSION}

To date, there is limited published studies that evaluated medication review services for specific diseases using RCT. In the UK, even after more than a decade of introducing medication-related advance services such as Medicines Use Review (MUR) and New Medicine Service, the impact of these services remains unknown. ${ }^{32,33}$ A meta-analysis by Aguiar et al. that included 22 RCTs involving pharmacist-led interventions (e.g educating patients, providing medication counselling, sending recommendations to the physician regarding change in medication, adjusting pharmacotherapy, and referring patients to other healthcare professionals) led to significant reduction in the mean $\mathrm{HbA} 1 \mathrm{c}$ by $0.85 \%$ when compared with the usual care group. ${ }^{34}$ Similar to another systematic review of community pharmacists' interventions by Chiazor et al., all the interventions in the RCT studies of Aguiar et al. were conducted in the community pharmacy, hospital, or

\begin{tabular}{|c|c|c|c|c|c|c|}
\hline \multirow{2}{*}{ Variables } & \multirow{2}{*}{$\mathbf{n}$} & \multicolumn{2}{|c|}{ Mean (SD) } & \multirow{2}{*}{$\begin{array}{c}\text { Within group } \\
\text { p-value }^{\mathrm{a}}\end{array}$} & \multirow{2}{*}{ Mean difference } & \multirow{2}{*}{$\begin{array}{c}\text { Interaction p-value } \\
\text { ITT }\end{array}$} \\
\hline & & Pre-intervention & Post-intervention & & & \\
\hline \multicolumn{7}{|c|}{ Knowledge } \\
\hline \multicolumn{7}{|l|}{ MDKT total score } \\
\hline HMR-CP group & 74 & $10.77(2.45)$ & $13.62(0.75)$ & $<0.001$ & $2.85(2.23)$ & $<0.001$ \\
\hline Control group & 83 & $10.23(2.01)$ & $10.99(1.71)$ & $<0.001$ & $0.76(1.07)$ & \\
\hline \multicolumn{7}{|c|}{ Quality of life } \\
\hline ED-5Q-5L utility value & & & & & & $<0.001$ \\
\hline HMR-CP group & 74 & $0.82(0.16)$ & $0.90(0.10)$ & $<0.001$ & $0.08(0.11)$ & \\
\hline Control group & 83 & $0.82(0.10)$ & $0.80(0.12)$ & 0.024 & $-0.01(4.59)$ & \\
\hline \multicolumn{7}{|c|}{ Lipid profiles } \\
\hline$T C(\mathrm{mmol} / \mathrm{L})$ & & & & & & $<0.001$ \\
\hline HMR-CP group & 74 & $5.69(1.43)$ & $5.39(1.22)$ & 0.002 & $-0.34(0.89)$ & \\
\hline Control group & 73 & $5.46(1.10)$ & $5.74(1.12)$ & $<0.001$ & $0.28(0.65)$ & \\
\hline$H D L(m m o l / L)$ & & & & & & 0.015 \\
\hline HMR-CP group & 74 & $1.28(0.32)$ & $1.25(0.31)$ & 0.163 & $-0.03(1.91)$ & \\
\hline Control group & 73 & $1.26(0.31)$ & $1.29(0.31)$ & 0.052 & $0.03(0.15)$ & \\
\hline
\end{tabular}


Rosli MR, Neoh CF, Wu DB, Hassan NW, Mahmud M, Rahimi A, Karuppannan M. Evaluation of home medication review for patients with type 2 diabetes mellitus by community pharmacists: a randomised controlled trial. Pharmacy Practice 2021 Jul-

https://doi.org/10.18549/PharmPract.2021.3.2397

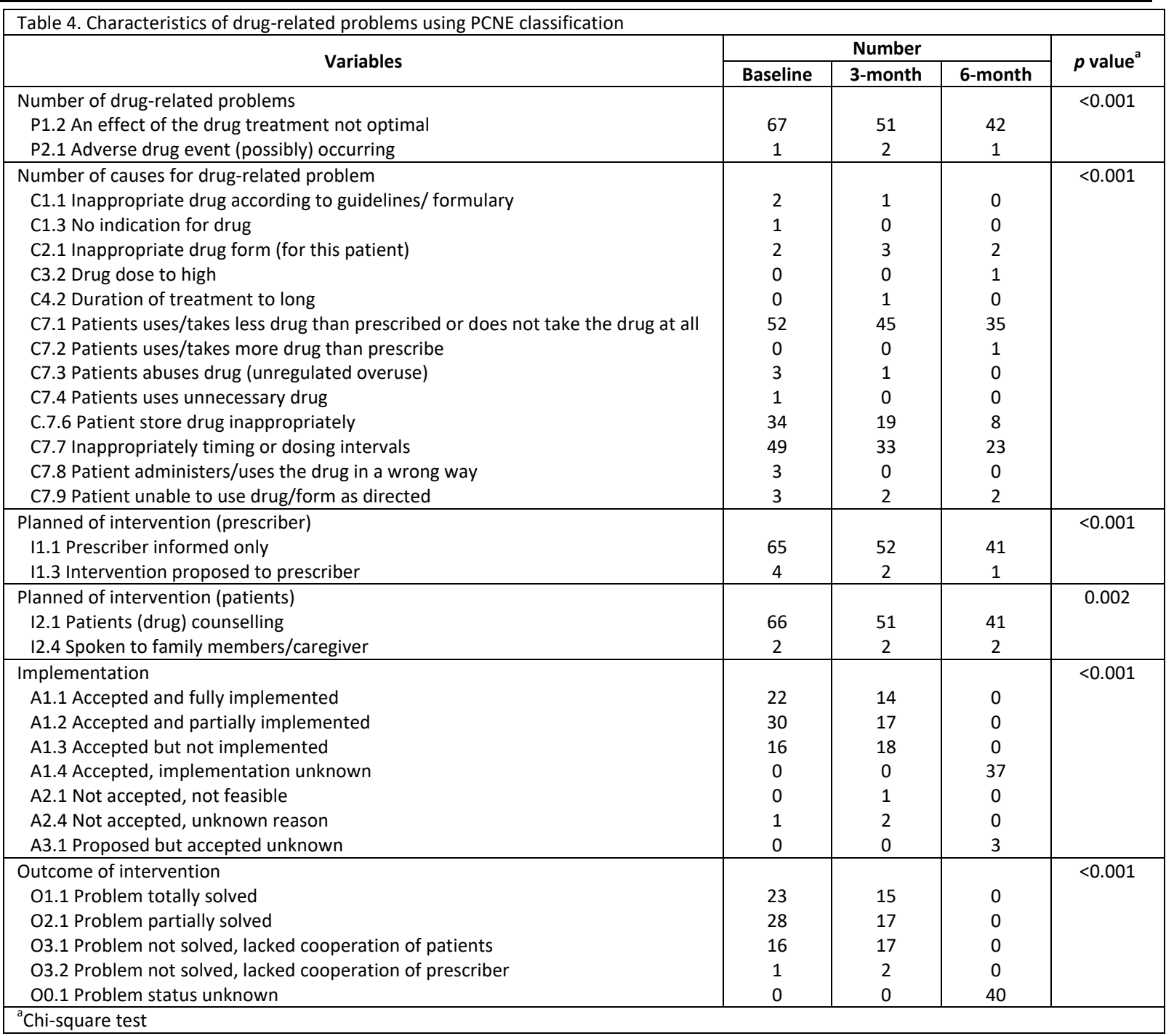

primary care setting. None of the studies were conducted in the setting of the patients' homes. ${ }^{34,35}$ Additionally, a recent umbrella review by Newman et al. that included nine review papers concluded that $\mathrm{CP}$-led interventions were associated with a significant reduction in $\mathrm{HbA1c}$, total cholesterol, and LDL among the diabetes patients. ${ }^{36}$ However, all the studies in the nine review papers involved different designs and locations of intervention. Some were face-to-face intervention in the outpatient and inpatient department or during patient's visit to the community pharmacy. Again, none of the studies involved HMR conducted by $\mathrm{CP}$ at the patient's home. Another study by Fink et al. (2019) found that T2DM patients who received clinical pharmacist care management of their disease reported a reduced $\mathrm{HbA} 1 \mathrm{c}$ by $1.6 \%$ compared to the control group with only a $0.9 \%$ reduction. ${ }^{37}$

To the best of our knowledge, this is the first RCT in Malaysia that evaluated the clinical and humanistic outcomes of the HMR program provided by $C P$ at the homes of diabetes patients. A scoping review by Stewart et al. (2019) on CP-led medication review in the UK highlighted that no RCT has been conducted to evaluate the clinical outcomes among diabetic patients. Most of the studies in the scoping review focused on barriers and facilitators of the implementation of medication review, patients' and pharmacists' perception towards the program, the process of conducting the consultation, and patient adherence. ${ }^{33}$ Furthermore, all the local studies in Malaysia involved only pharmacists from health clinics/hospitals who provided HMR. ${ }^{9,10,38,39}$ In addition, most of the studies from other countries involved pharmacist-led medication review at healthcare provider settings. Different countries practised different ways of implementing pharmacist-led medication reviews. For example, MUR was used in the UK and New Zealand, whereas the US used Medication Therapy Management (MTM) and Australia practised Home Medication Review (HMR). ${ }^{40}$ For MUR, the consultation takes place at community pharmacy. ${ }^{41}$ As for MTM, the medication review is carried out at various healthcare premises. ${ }^{42}$ Lastly, for HMR, the medication review takes place at the patient's home. ${ }^{43}$ However, the HMR service in Australia is slightly different from the current HMR-CP project in Malaysia, in which the need for HMR is requested by government MO/FMS. Comparatively, the HMR services in Australia can be ordered by the patient's general practitioner, community pharmacist, accredited pharmacists, patients, and also a caregiver. ${ }^{43}$ According to the report "Implementing and evaluating a parallel postdischarge Home Medication Review (HMR) model" 
Rosli MR, Neoh CF, Wu DB, Hassan NW, Mahmud M, Rahimi A, Karuppannan M. Evaluation of home medication review for patients with type 2 diabetes mellitus by community pharmacists: a randomised controlled trial. Pharmacy Practice 2021 Jul-

https://doi.org/10.18549/PharmPract.2021.3.2397

\begin{tabular}{|c|c|c|c|c|c|}
\hline \multirow{2}{*}{ Variables } & \multirow{2}{*}{$\mathbf{n}$} & \multicolumn{3}{|c|}{ Mean (SD) } & \multirow{2}{*}{ p-value ${ }^{a}$} \\
\hline & & Baseline & 3-month & 6-month & \\
\hline Pill counting adherence ratio (PCAR) & 74 & $0.20(0.21)$ & $0.31(0.25)$ & $0.51(0.28)$ & $<0.001$ \\
\hline Cost of medication wastage (MYR) & 74 & $21.73(34.86)$ & $15.08(14.98)$ & $12.55(16.41)$ & 0.014 \\
\hline
\end{tabular}

published by The Pharmacy Guild of Australia, several barriers from both the perspectives of patients and pharmacists might limit the implementation of HMR, such as cultural issues, language differences, and privacy. ${ }^{44}$ Nevertheless, in this study, all the community pharmacists involved hailed from the same region, thus minimising the potential barriers of cultural and language issues.

In view of the different settings between this RCT whereby community pharmacists performed HMR at patient's homes compared to other published studies, the results cannot be directly compared. Therefore, most of the results were compared with studies that involved health clinic/hospital pharmacists that provided HMR in the Malaysian setting. Generally, our study showed a significant improvement in glycaemic control (i.e. reductions in $\mathrm{HbA} 1 \mathrm{c}$ and $F B G$ ) in the HMR-CP group compared to the control group. This is in line with other studies that involved pharmacist-led medication review. ${ }^{9,10,38}$ Based on the positive findings in our study, it is obvious that the job scope of the community pharmacists can also be expanded to the patients' home apart from the usual community pharmacy setting. This can be considered as one of the extended services offered by the $\mathrm{CP}$ in the future.

During the first visit of HMR-CP, it was noted that most of the patients took their anti-diabetic medications at an inappropriate time or dosing interval $(n=49,66.2 \%)$. Many of them also took medicine of lower dosage than the one prescribed to them or did not take medicine at all $(n=54$, $70.3 \%)$. Slightly less than half of them $(n=34,45.9 \%)$ stored their drugs inappropriately, especially insulin. This study also showed that the increase in the knowledge about the disease and better adherence were correlated with a decrease of $\mathrm{HbA1C}$ in the intervention group. This finding was in concordance with a previous study in which lower knowledge about diabetes and non-adherence were independently correlated with an increase of HbA1c. ${ }^{45}$ In the current study, most of the DRP were resolved by the second and third HMR-CP visits as a result of better adherence towards medication and more favourable glycemic control among the patients who received HMRCP. In other words, significant improvements in patients' adherence and knowledge about diabetes could be the underlying reasons for the improved glycaemic control, as noted in this trial.

It is well acknowledged that diabetic patients require personalised treatment plan in accordance with their daily activities, particularly when lifestyle modifications have failed to control their blood glucose. ${ }^{46}$ Therefore, home visits under the HMR-CP program can establish a good relationship and trust between the healthcare provider (i.e. community pharmacists) and the diabetic patients. This can further improve the patients' understanding of their medications and subsequently lead to an increased adherence to their medicines. Apart from that, patients will also be comfortable to inform the healthcare provider confidently about their medical problems at home, as compared to the standard healthcare setting in a routine clinic whereby the patients may sometimes feel awkward to share their problems due to the lack of privacy as a result of the busy environment. ${ }^{47}$

In this RCT, the changes in anthropometric parameters such as weight $(p=0.409)$ and BMI $(p=0.575)$ did not differ significantly between the groups over time. During the HMR-CP visit, the diabetic patients were encouraged to carry out lifestyle modifications such as physical activities to reduce their weight and BMI. However, since most of the patients were more than 60 years old, exercise might be difficult in this age group. This is further strengthened by previous studies that showed a significant negative relationship between age and physical activity level among the Malaysian population. ${ }^{48,49}$ In another study conducted in Kelantan, the majority of respondents $(73.8 \%)$ suffered from chronic diseases and also had sedentary lifestyles. ${ }^{50}$

Furthermore, changes in the utility and MDKT scores preand post-intervention were significant between groups $(p<0.001)$. Both utility value and MDKT score increased significantly over time in the HMR-CP group at 6-month follow-up. For the control group, the MDKT score also increased significantly over time. This finding is in line with a previous Malaysian study that investigated the impact of HMR conducted by health clinic pharmacists among diabetes patients. ${ }^{10}$ Given that the T2DM patients in the HMR-CP group were reported to have better glycaemic control in this trial, this would likely result in an increased QoL. Additionally, a similar observation was noted in a local study that assessed the diabetic patients' QoL following HMR performed by health clinic pharmacists. ${ }^{9}$

With regard to hospitalisation, diabetic patients are associated with a higher rate of hospitalisation due to the complications of diabetes such as severe dysglycemia. ${ }^{51}$ However, in this trial, the incidence of hospitalisation was not significantly different between both groups [HMR-CP group, $n=3$ (3.6\%), control group, $n=6(7.2 \%) ; p=0.304]$. A previous study in Singapore showed that better medication adherence can reduce hospital admission among diabetic patients. $^{52}$ In another study, elderly patients with a high risk of DRPs showed reduced readmission and emergency visits after receiving HMR from pharmacists. ${ }^{53}$ However, it is important to note that the incidence of hospitalisation in this study could be under-reported as it was self-reported by the patients.

In the intervention group, HMR-CP significantly increased the patients; PCAR from 0.20 at baseline to 0.51 after 6 months $(p<0.001)$. This was in parallel with a significant reduction in the cost of medication wastage $(p=0.014)$. The development of HMR-CP has shown an increase in adherence. However, the mean rate of medication adherence in diabetic patients is still far from optimal. At the 6 -month of intervention, PCAR is only $51 \%$, and the 
adherence level of at least $90 \%$ was defined as acceptable. ${ }^{54}$ Pharmacists play an important role in advising patients to reduce medication wastage and to return the excess medication. ${ }^{55}$ The intervention group was advised by community pharmacists during each home visit to return their remaining medication when collecting their monthly refill at the health clinic. By comparison, the usage of medication by the control group at home could not be monitored. The reduction of medication wastage can help to minimise government expenditure on medication. Even though pharmacists have different ways to eliminate drug waste through the pharmaceutical supply chain, not all are widely implemented. ${ }^{55}$ The reduction of medication wastage and the subsequent cost saving were in line with a study by Mun (2015) in which medication wastage was reduced by $26.5 \%$ after 6 months of HMR. ${ }^{39}$

Furthermore, greater medication adherence among diabetic patients has been associated with better clinical outcomes as optimum effectiveness of pharmacotherapy can be achieved. ${ }^{56}$ In this study, the improved adherence rate was in line with other interventional studies (i.e. HMR conducted by health clinic and hospital pharmacists) among diabetic patients. ${ }^{9,10,26,38,39}$ Similarly, a significant increase in medication adherence was reported among patients who received medication review by $\mathrm{CP}$ at the community pharmacies in the UK. ${ }^{57}$

In terms of medication regime, T2DM patients usually have a complicated regimen. ${ }^{58}$ Even without the use of insulin, medication compliance can be challenging among them. Of note, the majority of T2DM patients are usually diagnosed with other comorbidities. ${ }^{59}$ On top of that, uncontrolled blood sugar results in both macro- and micro-vascular complications including blindness, kidney failure, lower limb amputation, stroke, and heart attack. ${ }^{3}$ Eventually, this translates into an immense impact on the government in terms of finance and human resources in disease treatment and the management of complications. ${ }^{60,61}$ DRPs are common among patients with a complex medication regimen, especially those with multiple co-morbidities such as dyslipidemia, hypertension, and cardiovascular disease. ${ }^{62}$ Interventions can be taken in accordance with the identified DRPs (i.e. appropriateness of treatment, adherence toward medications in terms of dosing and timing) in the form of HMR. By implementing HMR, this patient population would greatly benefit from improved health literacy and enhanced medication adherence. Hence, it would result in improved clinical outcomes and the QoL of the patients.

In this RCT, the number of DRP based on the PCNE classification $(p<0.001)$ was significantly reduced across the three time-points. The common DRP reported by patients in the HMR-CP group included suboptimal effects of the drug treatment as a result of non-adherence or taking lower than prescribed dose, inappropriate insulin storage, and inappropriate timing or dosing interval. This is consistent with the previous findings that most diabetic patients experienced problems related to adherence and compliance. ${ }^{63}$ Some of these problems require attention from the prescriber to modify the dose or type of medication if there are adherence issues or the medication is inappropriate for the patient's condition. By including
FMS/MO during HMR sessions, there will be better communication between community pharmacists, $\mathrm{FMS} / \mathrm{MO}$, and patients. In short, a collaborative care model that involves healthcare professionals from both public and private settings can further optimise patient care in Malaysia.

In this study, HMR-CP was proven to be the first publicprivate partnership program in Malaysia that showed a positive impact on certain clinical outcomes. HMR-CP can be the way forward for the $\mathrm{MOH}$, Malaysia in the expansion of the HMR services. Budget allocation should be reserved for the implementation of the HMR service, not unlike other developed countries. ${ }^{43}$ In Australia, the Diabetes Medication Assistance Services (DMAS) by trained community pharmacists has shown significant health benefits among diabetic patients in terms of improved glycaemic control, reduced risk of non-adherence to medications, and increased knowledge about diabetes selfmanagement. ${ }^{64}$

There are several limitations to this study. In Malaysia, the prevalence of DM was shown to be the highest among the Indian ethnic group. ${ }^{65}$ However, there were no Indian participants in this study, likely because Indians account for the lowest percentage of the ethnic population in Kelantan $(0.27 \%){ }^{66}$ Besides, only one health clinic in Kelantan was included in this trial. As such, the findings of this trial may not be generalisable to the entire Malaysian diabetes population. Furthermore, the QoL, knowledge of diabetes, and hospitalisation were self-reported by the patients and thus subjected to bias. In addition, the access to patients' profiles was only limited to the community pharmacists. Therefore, the community pharmacist had to conduct the HMR-CP session with minimal information provided by the researcher. In the future, an integrated online patient database that can be accessed by healthcare professionals including community pharmacists can improve the access to the individual patient's medical needs. There could be social-desirability bias between the control and intervention groups given the different modes of data collection (i.e phone calls versus face-to-face) were used for quality of life and diabetic knowledge. Lastly, future studies can consider more frequent interactions between the community pharmacists and T2DM patients and a shorter follow-up interval rather than every 3 months as proposed in this study.

\section{CONCLUSIONS}

Apart from possessing the necessary skills and knowledge, the community pharmacists in Malaysia are also well positioned in the healthcare system to engage further in the provision of care for people with multiple chronic diseases. The 6-month HMR-CP programme showed the feasibility of engaging community pharmacists to provide extended services such as HMR. They can also be incorporated into the collaborative care model that includes $\mathrm{FMS} / \mathrm{MO}$ in the government sector and community pharmacists in the private sector. Such collaboration will provide a positive impact on the clinical outcomes of diabetic patients. Based on this study, the HMR-CP program significantly improved the T2DM patient's glycaemic control, QoL, medication adherence, 
Rosli MR, Neoh CF, Wu DB, Hassan NW, Mahmud M, Rahimi A, Karuppannan M. Evaluation of home medication review for patients with type 2 diabetes mellitus by community pharmacists: a randomised controlled trial. Pharmacy Practice 2021 Jul-

and knowledge about diabetes. At the same time, it also reduced the number of DRP and cost of medication wastage. Future studies can explore the economic sustainability of the programme especially with expanded implementation by the $\mathrm{MOH}$.

\section{CONFLICT OF INTEREST}

NWH, MM, and AR are staff working at the recruitment site of this trial.

\section{FUNDING}

The authors received no financial support for the research, authorship or publication of this article.
https://doi.org/10.18549/PharmPract.2021.3.2397

\section{AUTHOR ROLES (CRediT)}

Conceptualization: MRR, CFN, MK.

Data curation: MRR, CFN, MK.

Formal analysis: MRR, CFN, DBW, MK.

Funding acquisition: MRR.

Investigation: $M R R, N W H, M M, A R$.

Methodology: MRR, CFN, MK.

Project administration: MRR, NWH, MM, AR.

Resources: MRR, CFN, MK.

Supervision: MRR, NWH, MM, AR.

Validation: MRR, CFN, MK.

Writing: original draft: MRR, CFN, DBW, MK.

Writing: review \& editing: MRR, CFN, DBW, MK.

\section{References}

1. Tabish SA. Is Diabetes Becoming the Biggest Epidemic of the Twenty-first Century?. Int J Health Sci (Qassim). 2007;1(2):V-VIII.

2. National Health and Morbility survey Malaysia: Ministry of Health; 2019.

3. World Health Organization. Global Report on Diabetes. Geneva: WHO; 2016.

4. Jokanovic N, Tan EC, Sudhakaran S, et al. Pharmacist-led medication review in community settings: An overview of systematic reviews. Res Social Adm Pharm. 2017;13(4):661-685. https://doi.org/10.1016/i.sapharm.2016.08.005

5. Brown H, Chong L, Edwards S, Gillespi S, Martin G, Petrei N, et al. Guidelines For Pharmacists Providing Home Medication Review (HMR) Services. https://www.ppaonline.com.au/wp-content/uploads/2019/01/PSA-Guidelines-forProviding-Home-Medicines-Review-HMR-Services.pdf (accessed Feb 29, 2018).

6. White L, Klinner C, Carter S. Consumer perspectives of the Australian Home Medicines Review Program: benefits and barriers. Res Social Adm Pharm. 2012;8(1):4-16. https://doi.org/10.1016/j.sapharm.2010.11.003

7. Home Medication Review Protocol. Malaysia: Ministry of Health; 2011.

8. Mohamad Rb, Haron NHb, Amri Ab. Home Care Pharmacy Services Protocol 2nd ed. Malaysia: Ministry of Health; 2019.

9. Alias NEB. The impact of home medication review in patients with type 2 diabetes mellitus living in rural areas of kuantan [master's thesis]. Malaysia: International Islamic University Malaysia; 2015.

10. Chow EP, Hassali MA, Saleem F, Aljadhey $\mathrm{H}$. Effects of pharmacist-led patient education on diabetes-related knowledge and medication adherence: A home-based study. Health Educ J. 2015;75(4):421-33. https://doi.org/10.1177\%2F0017896915597021

11. Papastergiou J, Zervas J, Li W, Rajan A. Home medication reviews by community pharmacists: Reaching out to homebound patients. Can Pharm J (Ott). 2013;146(3):139-142. https://doi.org/10.1177/1715163513487830

12. Mossialos E, Courtin E, Naci H, et al. From "retailers" to health care providers: Transforming the role of community pharmacists in chronic disease management. Health Policy. 2015;119(5):628-639. https://doi.org/10.1016/j.healthpol.2015.02.007

13. Alotaibi HS, Shivanandappa TB, Nagarethinam S. Contribution of community pharmacists in educating the asthma patients. Saudi Pharm J. 2016;24(6):685-688. https://doi.org/10.1016/j.jsps.2015.06.002

14. Tan CLH, Gan VBY. Pharmacy Value Added Services: Early Begininings, Current Implementation, And Challenges From The Malaysian Experience. Indian J Pharm Educ Res. 2016;50(3):335-343. https://doi.org/10.5530/ijper.50.3.4

15. Bardet JD, Vo TH, Bedouch P, Allenet B. Physicians and community pharmacists collaboration in primary care: A review of specific models. Res Social Adm Pharm. 2015;11(5):602-622. https://doi.org/10.1016/j.sapharm.2014.12.003

16. Population Distribution by Local Authority Areas and Mukims. Malaysia: Department of Statistics 2010.

17. National Diabetes Registry Report. Malaysia: Ministry of Health; 2013.

18. Schnedl WJ, Krause R, Halwachs-Baumann G, Trinker M, Lipp RW, Krejs GJ. Evaluation of HbA1c determination methods in patients with hemoglobinopathies. Diabetes Care. 2000;23(3):339-344. https://doi.org/10.2337/diacare.23.3.339

19. Kuo IC, Lin HY, Niu SW, et al. Glycated Hemoglobin and Outcomes in Patients with Advanced Diabetic Chronic Kidney Disease. Sci Rep. 2016;6:20028. https://doi.org/10.1038/srep20028

20. Stratton IM, Adler AI, Neil HA, et al. Association of glycaemia with macrovascular and microvascular complications of type 2 diabetes (UKPDS 35): prospective observational study. BMJ. 2000;321(7258):405-412. https://doi.org/10.1136/bmi.321.7258.405

21. International Expert Committee. International Expert Committee report on the role of the $\mathrm{A} 1 \mathrm{C}$ assay in the diagnosis of diabetes. Diabetes Care. 2009;32(7):1327-1334. https://doi.org/10.2337/dc09-9033

22. Management of Type 2 Diabetes Mellitus Malaysia: Ministry of Health; 2015.

23. Classification for Drug related problems. http://www.pcne.org/upload/files/230 PCNE classification V8-02.pdf (accessed Feb 29, 2018).

24. Kalogianni A. Factors affect in patient adherence to medication regimen Health Sci J. 2011;5(3):157-158 
Rosli MR, Neoh CF, Wu DB, Hassan NW, Mahmud M, Rahimi A, Karuppannan M. Evaluation of home medication review for patients with type 2 diabetes mellitus by community pharmacists: a randomised controlled trial. Pharmacy Practice 2021 JulSep;19(3):2397.

https://doi.org/10.18549/PharmPract.2021.3.2397

25. Wu P, Johnson BA, Nachega JB, et al. The combination of pill count and self-reported adherence is a strong predictor of first-line ART failure for adults in South Africa. Curr HIV Res. 2014;12(5):366-375. https://doi.org/10.2174/1570162x1205141121102501

26. Butt M, Mhd Ali A, Bakry MM, Mustafa N. Impact of a pharmacist led diabetes mellitus intervention on HbA1c, medication adherence and quality of life: A randomised controlled study. Saudi Pharm J. 2016;24(1):40-48. https://doi.org/10.1016/i.jsps.2015.02.023

27. Group TE. EQ-5D-5L User Guide. https://eurogol.org/publications/user-guides/ (accessed Dec 20, 2020).

28. Shafie AA, Vasan Thakumar A, Lim CJ, Luo N, Rand-Hendriksen K, Md Yusof FA. EQ-5D-5L Valuation for the Malaysian Population. Pharmacoeconomics. 2019;37(5):715-725. https://doi.org/10.1007/s40273-018-0758-7

29. Qahtani LA, Alqarni A, S. M, Mohamud, Masuadi E, Aldhubayee M. Michigan Diabetes Knowledge Test: translation and validation study of the Arabic version. Int J Acad Sci Res. 2016;4(1):121-125.

30. Al-Qazaz H, Hassali M, Shafie A, Sulaiman S, Sundram S. The 14-item Michigan Diabetes Knowledge Test: Translation and validation study of the Malaysian version. Pract Diabetes Int. 2010;27:238-241. https://doi.org/10.1002/pdi.1495

31. Karanicolas PJ, Farrokhyar F, Bhandari M. Practical tips for surgical research: blinding: who, what, when, why, how?. Can J Surg. 2010;53(5):345-348.

32. Latif A. Community pharmacy Medicines Use Review: current challenges. Integr Pharm Res Pract. 2017;7:83-92.

33. Stewart D, Whittlesea C, Dhital R, Newbould L, McCambridge J. Community pharmacist led medication reviews in the UK: A scoping review of the medicines use review and the new medicine service literatures. Res Social Adm Pharm. 2020;16(2):111-122. https://doi.org/10.1016/i.sapharm.2019.04.010

34. Aguiar PM, Brito Gde C, Lima Tde M, Santos AP, Lyra DP Jr, Storpirtis S. Investigating Sources of Heterogeneity in Randomized Controlled Trials of the Effects of Pharmacist Interventions on Glycemic Control in Type 2 Diabetic Patients: A Systematic Review and Meta-Analysis. PLoS One. 2016;11(3):e0150999. https://doi.org/10.1371/journal.pone.0150999

35. Ifeanyi Chiazor E, Evans M, van Woerden H, Oparah AC. A Systematic Review of Community Pharmacists' Interventions in Reducing Major Risk Factors for Cardiovascular Disease. Value Health Reg Issues. 2015;7:9-21. https://doi.org/10.1016/j.vhri.2015.03.002

36. Newman TV, San-Juan-Rodriguez A, Parekh N, et al. Impact of community pharmacist-led interventions in chronic disease management on clinical, utilization, and economic outcomes: An umbrella review. Res Social Adm Pharm. 2020;16(9):1155-1165. https://doi.org/10.1016/j.sapharm.2019.12.016

37. Fink RM, Mooney EV, Saseen JJ, Billups SJ. A comparison of clinical pharmacist management of type 2 diabetes versus usual care in a federally qualified health center. Pharm Pract (Granada). 2019;17(4):1618. https://doi.org/10.18549/pharmpract.2019.4.1618

38. Sidek NN, Xin LH, Nurul W, et al. Impact of Pharmacists' Involvement in Home Medication Review (HMR) Among Stroke Patients in Terengganu, Malaysia. Int J Pharm Pharm Res. 2017;11(1):77-86.

39. Mun TY. Evaluation of the impact of Home Medication Review Program on adherence among patients diagnosed with schizophrenia at Kinta district, Malaysia. Malaysia: USM; 2015.

40. Hatah E, Braund R, Tordoff J, Duffull SB. A systematic review and meta-analysis of pharmacist-led fee-for-services medication review. Br J Clin Pharmacol. 2014;77(1):102-115. https://doi.org/10.1111/bcp.12140

41. MUR premises requirements. http://archive.psnc.org.uk/pages/mur premises requirements.html (accessed Dec 20 2020).

42. Bennett MS, Chater RW, Croley KS, et al. Medication therapy management in pharmacy practice: core elements of an MTM service model. Washington: American Pharmacist Association; 2008.

43. Australian Government. Program Rules Home Medicines Review. https://www.ppaonline.com.au/wpcontent/uploads/2019/01/HMR-Program-Rules.pdf (accessed Dec 20, 2020).

44. The Pharmacy Guild of Australia. Implementing and evaluating a parallel post-discharge Home Medication Review (HMR) model. http://6cpa.com.au/wp-content/uploads/Implementing-and-Evaluating-a-Parallel-Post-discharge-Home-MedicinesReview-HMR-Model-Full-Final-Report.pdf (accessed Dec 20, 2020).

45. Andrade CS, Ribeiro GS, Santos CAST, Neves RCS, Moreira ED Jr. Factors associated with high levels of glycated haemoglobin in patients with type 1 diabetes: a multicentre study in Brazil. BMJ Open. 2017;7(12):e018094. https://doi.org/10.1136/bmjopen-2017-018094

46. Asif M. The prevention and control the type-2 diabetes by changing lifestyle and dietary pattern. J Educ Health Promot. 2014;3:1. https://doi.org/10.4103/2277-9531.127541

47. Hardavella G, Aamli-Gaagnat A, Frille A, Saad N, Niculescu A, Powell P. Top tips to deal with challenging situations: doctor-patient interactions. Breathe (Sheff). 2017;13(2):129-135. https://doi.org/10.1183/20734735.006616

48. Cai Lian T, Bonn G, Si Han Y, Chin Choo Y, Chee Piau W. Physical Activity and Its Correlates among Adults in Malaysia: A Cross-Sectional Descriptive Study. PLoS One. 2016;11(6):e0157730. https://doi.org/10.1371/journal.pone.0157730

49. Cheah YK, Lim HK, Kee CC. Demographic and lifestyle determinants of time spent in physical activity among Malaysian adolescents [published correction appears in Int J Pediatr Adolesc Med. 2020 Dec;7(4):212]. Int J Pediatr Adolesc Med. 2018;5(2):49-54. https://doi.org/10.1016/j.ijpam.2018.02.001

50. Hami R. Older people physical activity assessment in Kelantan, Malaysia. Int J Public Health Clin Sci. 2017;4:357.

51. Khalid JM, Raluy-Callado M, Curtis BH, Boye KS, Maguire A, Reaney M. Rates and risk of hospitalisation among patients with type 2 diabetes: retrospective cohort study using the UK General Practice Research Database linked to English Hospital Episode Statistics. Int J Clin Pract. 2014;68(1):40-48. https://doi.org/10.1111/ijcp.12265

52. Bussell JK, Cha E, Grant YE, Schwartz DD, Young LA. Ways Health Care Providers Can Promote Better Medication Adherence. Clin Diabetes. 2017;35(3):171-177. https://doi.org/10.2337/cd016-0029 
Rosli MR, Neoh CF, Wu DB, Hassan NW, Mahmud M, Rahimi A, Karuppannan M. Evaluation of home medication review for patients with type 2 diabetes mellitus by community pharmacists: a randomised controlled trial. Pharmacy Practice 2021 JulSep;19(3):2397.

https://doi.org/10.18549/PharmPract.2021.3.2397

53. Cheen MHH, Goon CP, Ong WC, et al. Evaluation of a care transition program with pharmacist-provided home-based medication review for elderly Singaporeans at high risk of readmissions. Int J Qual Health Care. 2017;29(2):200-205. https://doi.org/10.1093/intahc/mzw150

54. van Onzenoort HA, Verberk WJ, Kessels AG, et al. Assessing medication adherence simultaneously by electronic monitoring and pill count in patients with mild-to-moderate hypertension. Am J Hypertens. 2010;23(2):149-154. https://doi.org/10.1038/ajh.2009.207

55. Bekker CL, Gardarsdottir H, Egberts ACG, Bouvy ML, van den Bemt BJF. Pharmacists' Activities to Reduce Medication Waste: An International Survey. Pharmacy (Basel). 2018;6(3):94. https://doi.org/10.3390/pharmacy6030094

56. Lin LK, Sun Y, Heng BH, Chew DEK, Chong PN. Medication adherence and glycemic control among newly diagnosed diabetes patients. BMJ Open Diabetes Res Care. 2017;5(1):e000429. https://doi.org/10.1136/bmjdrc-2017-000429

57. Elliott RA, Boyd MJ, Salema NE, et al. Supporting adherence for people starting a new medication for a long-term condition through community pharmacies: a pragmatic randomised controlled trial of the New Medicine Service. BMJ Qual Saf. 2016;25(10):747-758. https://doi.org/10.1136/bmias-2015-004400

58. Marín-Peñalver JJ, Martín-Timón I, Sevillano-Collantes C, Del Cañizo-Gómez FJ. Update on the treatment of type 2 diabetes mellitus. World J Diabetes. 2016;7(17):354-395. https://doi.org/10.4239/wjd.v7.i17.354

59. Nowakowska M, Zghebi SS, Ashcroft DM, et al. The comorbidity burden of type 2 diabetes mellitus: patterns, clusters and predictions from a large English primary care cohort. BMC Med. 2019;17(1):145. https://doi.org/10.1186/s12916-0191373-y

60. Walker IF, Garbe F, Wright J, et al. The Economic Costs of Cardiovascular Disease, Diabetes Mellitus, and Associated Complications in South Asia: A Systematic Review. Value Health Reg Issues. 2018;15:12-26. https://doi.org/10.1016/.j.vhri.2017.05.003

61. Abu-Rmeileh NME, Ghandour R, Mataria A, Awawda S, Jabr S, O'Flaherty M. Time to act on diabetes mellitus prevention in the West Bank, oPt: Current and future direct cost of diabetes and its complications. Obesity Medicine. 2017;6:18-22. https://doi.org/10.1016/i.obmed.2017.04.001

62. Zaman Huri H, Chai Ling L. Drug-related problems in type 2 diabetes mellitus patients with dyslipidemia. BMC Public Health. 2013;13:1192. https://doi.org/10.1186/1471-2458-13-1192

63. Gangwar SS, Monisha N, Nachiya J, Narasingarao K, Parimalakrishnan S, Singh SP. Impact of medication and psychological behaviour assessment by community pharmacists in type 2 diabetes mellitus patients after hospital stay. Afr Health Sci. 2014;14(3):539-550. https://doi.org/10.4314/ahs.v14i3.7

64. Mitchell B, Armour C, Lee M, et al. Diabetes Medication Assistance Service: the pharmacist's role in supporting patient self-management of type 2 diabetes (T2DM) in Australia. Patient Educ Couns. 2011;83(3):288-294 https://doi.org/10.1016/i.pec.2011.04.027

65. National Health and Morbidity Survey. Malaysia: Ministry of Health; 2015.

66. Data Asas 2015-2016. Kelantan: Kelantan State Government; 2016. 